\title{
Cerebral blood flow and blood viscosity in patients with polycythaemia secondary to hypoxic lung disease
}

\author{
J P H WADE，T C PEARSON， R W ROSS RUSSELL， G WETHERLEY-MEIN
}

\begin{abstract}
Blood viscosity, cerebral blood flow (CBF) and cerebral oxygen carriage (CBF $\times$ arterial oxygen content) were measured in 12 patients with polycythaemia secondary to hypoxic lung disease. CBF and cerebral oxygen carriage were both significantly higher than in a comparative group of 20 patients with raised packed cell volumes and normal lung function. The patients with secondary polycythaemia then underwent venesection and their mean packed cell volume fell from 0.613 to $0 \cdot 495$. This led to a consistent reduction in blood viscosity, which fell by $44 \%$ at a low shear rate $(0.67 / \mathrm{s})$ and $33 \%$ at a high shear rate $(0.91 / \mathrm{s})$. CBF rose by $21 \%(\mathrm{p}<0.01)$, but cerebral oxygen carriage did not significantly increase in the group as a whole.

Four of the patients with secondary polycythaemia had complained of episodes of confusion before venesection, which improved considerably once the packed cell volume had been lowered. Headache was relieved in a further two patients and none of the subjects was adversely affected by venesection. It was not possible, however, to show a correlation between symptomatic improvement and an increase in cerebral oxygen carriage.
\end{abstract}

\section{Introduction}

Patients with chronic hypoxic lung disease may develop polycythaemia in response to reduced arterial oxygen saturation. There is a significant overall correlation between the increase in

St Thomas's Hospital, London SE1

J P H WADE, MRCP, registrar in neurology

T C PEARSON, MD, MRCPATH, senior lecturer in haematology

R W ROSS RUSSELL, MD, FRCP, consultant neurologist

G WETHERI.EY-MEIN, MD, FRCP, professor of hacmatology the red cell mass and the degree of arterial oxygen saturation, ${ }^{1}$ although in some patients the erythropoietic response appears exaggerated ${ }^{2}$ whereas in others the red cell mass is substantially lower than predicted on the basis of the normal response to chronic hypoxia. ${ }^{3}{ }^{4}$ The raised packed cell volume (PCV) could be regarded as a compensatory mechanism designed to increase the arterial oxygen capacity, and treatment designed to lower it may therefore be inappropriate. When the PCV is increased, however, so too is the blood viscosity, ${ }^{5}$ and tissue oxygen delivery will be facilitated only if blood flow to the tissues is maintained.

There is considerable evidence suggesting that the PCV may be clinically important, influencing blood flow through the tissues. In patients with polycythaemia rubra vera (primary proliferative polycythaemia) cerebral blood flow (CBF) is low but returns to normal once the PCV has been reduced by venesection, and the increase in flow more than compensates for the calculated decrease in the oxygen-carrying capacity of the blood. ${ }^{\circ}$ Similar findings have been reported when the PCV is lowered in patients with relative polycythaemia. ${ }^{7}$ Some patients without polycythaemia but with intermittent claudication show an improvement in walking distance and an associated increase in limb blood flow after a reduction in PCV. ${ }^{8}$

Two studies have reported a significant reduction in pulmonary vascular resistance after haemodilution in patients with polycythaemia secondary to hypoxic lung disease, ${ }^{910}$ and in one report objective measures of work capacity improved in some patients. ${ }^{9}$ The raised PCV may therefore not be advantageous in this group of patients and a policy designed to reduce the PCV to below 0.50 could therefore be advocated.

Patients with polycythaemia secondary to hypoxic lung disease often complain of lethargy and drowsiness, which have been attributed to cerebral hypoxia and which may improve after a reduction in PCV. We measured blood viscosity, $\mathrm{CBF}$, and cerebral oxygen carriage $(\mathrm{CBF} \times$ arterial oxygen content) in patients with polycythaemia due to lung disease and compared the results with those from subjects with raised PCV but normal lung function. The patients with secondary polycythaemia then underwent venesection to reduce PCV, after which the measurements were repeated to assess any change in the cerebral circulation. 


\section{Patients and methods}

CBF was measured in 12 patients with polycythaemia secondary to hypoxic lung disease (secondary group) and in 20 patients with a raised PCV with no identifiable cause (primary group). Blood was taken for measuring PCV, viscosity, arterial gases, arterial oxygen content, and oxygen dissociation curves at the same time as the CBF estimation. The 12 patients in the secondary group then underwent venesection and the study was repeated once the PCV had been lowered. All patients gave their informed consent.

Secondary group-The mean age of the 12 patients (nine men) in the secondary group was $62+6$ years. Eleven gave a history consistent with the diagnosis of chronic bronchitis, ${ }^{11}$ and pulmonary function tests showed irreversible airflow obstruction with overinflated lungs. The twelfth patient had suffered poliomyelitis as a child and had residual weakness of the chest wall muscles and right diaphragm, and his lung volumes were less than predicted. Eight of the patients were receiving diuretics for episodes of cor pulmonale, but drug regimens were not altered between the first and second studies. All the subjects were outpatients and had been referred to the department of haematology for venesection. Four complained of episodes of drowsiness and confusion, and a further two had severe headache. One subject had suffered a minor cerebrovascular accident two years before the study, but none of the patients had focal neurological signs. In nine patients the red cell mass was unequivocally increased, ${ }^{12}$ and in the remaining three (PCV 0.681, 0.690, and 0.720) this investigation was omitted. After the first CBF measurement the PCV was lowered by venesection, and $300-450 \mathrm{ml}$ of blood was removed each week until the PCV was less than 0.520. This took an average of seven weeks (range 4-12) and the second study was performed at least five days after the last venesection.

Primary group-The primary group comprised 20 patients with a raised PCV and normal lung function. On the basis of red cell mass and plasma volume measurements and other investigations six were considered to have polycythaemia rubra vera, four had idiopathic erythrocytosis, ${ }^{13}$ and 10 had relative polycythaemia. ${ }^{14}$ One of the patients had Parkinson's disease and one had suffered three transient ischaemic attacks, but none of the others had symptoms or signs to suggest neurological disease. They had presented with: hypertension (5), pruritis (2), gastritis (2), intermittent claudication (2), angina (2), chest infection (1), digital infarction (1), and abnormal routine blood count (5).

Cerebral blood flow-CBF was measured by an intravenous ${ }^{133} \mathrm{Xe}$ technique, ${ }^{15}$ which is a modification of the original inhalation method described by Obrist et al. ${ }^{16} 5-8 \mathrm{mCi}^{133} \mathrm{Xe}$, dissolved in saline, was injected into a peripheral vein, and the cerebral clearance curves were monitored using six sodium iodide detectors of $25 \mathrm{~mm}$ diameter arranged symmetrically around the head. In the standard technique expired air ${ }^{133} \mathrm{Xe}$ activity is also monitored because the method relies on an accurate measure of the arterial ${ }^{133} \mathrm{Xe}$ recirculation to the brain, and in patients with normal lungs end-tidal air $\mathrm{Xe}$ concentrations reflect arterial Xe concentrations. ${ }^{17}$ If lung function is disturbed, however, this assumption is no longer valid, ${ }^{17}$ and a method of continuous arterial sampling was therefore developed for use in the present study. The radial artery was cannulated, under local anaesthesia, with a 22-gauge Medicut cannula, and blood was withdrawn at $10 \mathrm{ml} / \mathrm{min}$ via a small-bore nylon tube to a glass spiral located within a scintillation counter. The method was validated by comparing the CBF results in six subjects with normal lungs using simultaneously derived end-tidal and arterial data to estimate recirculating ${ }^{133} \mathrm{Xe}$. Close agreement was found between the two methods. Since blood was withdrawn at $10 \mathrm{ml} / \mathrm{min}$, investigation time was necessarily limited, and the flow index used in this paper was derived from the slope of the first minute of the cerebral clearance curves displayed semi-logarithmically. ${ }^{18}$ The CBF values were corrected for the patient's haemoglobin level since this is known to influence the relative solubility of xenon between blood and brain. ${ }^{19} \mathrm{CBF}$ results can also be corrected for changes in $\mathrm{PaCO}_{2}$ levels, but this was not considered justified because CBF tends to return to normal under conditions of chronic hypercapnia. ${ }^{20}$ Each $\mathrm{CBF}$ value refers to the mean result from the six regions of the head.

$P C V$ and blood viscosity-Blood was taken without stasis from an antecubital vein and anticoagulated with lithium heparin $(12.5 \mathrm{U} / \mathrm{ml})$. PCV was measured using a microHaematocrit method and 10 minutes' centrifugation. Blood viscosity was measured at $37 \mathrm{C}$ over a wide range of shear rates using a Contraves low-shear 30 coaxial viscometer, and values at a low shear rate $(0.67 / \mathrm{s})$ and a high shear rate $(91 / \mathrm{s})$ are quoted.

Blood gases and arterial oxygen content-Blood was taken from the radial artery at the end of each CBF measurement. The samples were kept in crushed ice, and the blood gases and $\mathrm{pH}$ were measured on an ABL 1 acid-base analyser (Radiometer, Copenhagen) within one hour of sampling. Oxygen content was measured using a Lex $0_{2}$ Con total oxygen content analyser (Lexington Instruments, Mass) after thorough mixing of the sample. This apparatus measures the total amount of oxygen in a $20-\mu \mathrm{l}$ sample of blood by displacing the bound oxygen with carbon monoxide and expresses the result in $\mathrm{ml} / 100 \mathrm{ml}$. Duplicate measurements were performed and accepted as valid if they were within $2 \%$ of each other.

Oxygen dissociation curve-Venous blood, anticoagulated with lithium heparin $(12.5 \mathrm{u} / \mathrm{ml})$, was used and the sample kept on ice for a maximum of two hours before measurement. The oxygen dissociation curve was plotted on an Aminco Haem-O-Scan analyser (Aminco, Maryland). With this apparatus $2 \mu \mathrm{l}$ of blood is maintained at $37^{\circ} \mathrm{C}$ in a humidified atmosphere and exposed to gas mixtures containing $5 \cdot 6^{\circ} \mathrm{CO}_{2}$ and a variable amount of $\mathrm{O}_{2}$. The partial pressure of $\mathrm{O}_{2}$ is monitored by a Clark electrode and the percentage oxyhaemoglobin assessed spectrophotometrically. The $5 \cdot 6^{\prime \prime \prime}, \mathrm{CO}_{2}$ stabilises the $\mathrm{pH}$ of the sample at $7 \cdot 40$ and no facilities are provided for actually measuring $\mathrm{pH}$. The $\mathrm{Po}_{2}$ value at which the haemoglobin was $50 \%$ saturated $\left(P_{50}\right)$ was read directly off the oxygen dissociation curve and the results refer to the mean of two readings, which were accepted as valid if the $P_{50}$ values were within $0.13 \mathrm{kPa}(1 \mathrm{~mm} \mathrm{Hg})$ of each other.

Statistical methods-When two groups were compared an unpaired $t$ test was used. The effect of venesection in subjects with secondary polycythaemia was assessed by use of the paired $t$ test with the patients acting as their own controls.

\section{Results}

Comparison between secondary and primary groups (table I)-The mean age of the patients in the secondary group was significantly higher than that of the primary group. Mean arterial blood pressure

TABLE I-Comparison of haematological data, CBF, and cerebral oxygen carriage between 20 patients with polycythaemia secondary to hypoxic lung disease (secondary group) and patients with primary polycythaemia (primary group). Results are means $+S D$

\begin{tabular}{|c|c|c|c|}
\hline & $\begin{array}{l}\text { Secondary group } \\
(\mathbf{n}=12)\end{array}$ & $\begin{array}{l}\text { Primary group } \\
\qquad(\mathrm{n}=20)\end{array}$ & Significance (p) \\
\hline $\begin{array}{l}\text { Age } \\
\text { MABP (mm Hg) } \\
\text { PCV } \\
\text { Blood viscosity }\left(\mathrm{mNsm}^{-2}\right)\end{array}$ & $\begin{aligned} 62 & : 6 \\
108 & : 13 \\
0.613 & : 0.062\end{aligned}$ & $\begin{array}{r:l}57 & 7 \\
110 & 13 \\
0.537 & 0.034\end{array}$ & $\begin{array}{l}\because 0.05 \\
\quad \text { NS } \\
=0.005\end{array}$ \\
\hline $\begin{array}{l}\text { Blood viscosity }\left(\mathrm{mNsm}^{-2}\right) \\
\text { at shear rates of: } \\
0.67 / \mathrm{s} \\
0.91 \mathrm{~s} \\
\mathrm{PaCO}_{2}(\mathrm{kPa}) \\
\mathrm{pH} \\
\mathrm{P}_{\text {so }}(\mathrm{kPa}) \\
\mathrm{CBF}(\mathrm{ml} / 100 \mathrm{~g} / \mathrm{min}) \\
\text { Cerebral oxygen carriage }\end{array}$ & $\begin{array}{r:l}69 \cdot 2 & 24 \cdot 8 \\
8 \cdot 08 & 2 \cdot 16 \\
7 \cdot 5 & 0 \cdot 9 \\
7 \cdot 37 & 0 \cdot 03 \\
3 \cdot 6 & 0 \cdot 2 \\
39 \cdot 1 & 8 \cdot 3\end{array}$ & 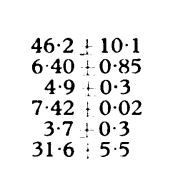 & $\begin{array}{l}0.01 \\
0.05 \\
00.005 \\
0.001 \\
\text { NS } \\
0.01\end{array}$ \\
\hline$(\mathrm{ml} / 100 \mathrm{~g} / \mathrm{min})$ & $7 \cdot 61: 1.42$ & $6.48: 1.03$ & 0.02 \\
\hline
\end{tabular}

Conversion: SI to traditional units $-\mathrm{PaCO}_{2}$, and $\mathrm{P}_{\mathrm{so}}: 1 \mathrm{kPa}=7.5 \mathrm{~mm} \mathrm{Hg}$. NS $=$ Not significant. MABP $=$ Mean arterial blood pressure.

was comparable in the two groups. Mean PCV was 0.613 in the secondary group and $0.537(\mathrm{p}<0.005)$ in the primary group. This explains the significant difference in mean blood viscosity values at shear rates of $0.67 / \mathrm{s}$ and $91 / \mathrm{s}$. The mean $\mathrm{PaCO}_{2}$ in the secondary group was significantly higher than in the primary group. The difference in mean $\mathrm{pH}$ was also highly significant. The mean $\mathbf{P}_{50}$ was similar in both groups and not significantly different from the normal for our laboratory, which is $3.7+0.2 \mathrm{kPa}(27.7+1.3 \mathrm{~mm} \mathrm{Hg})$ based on 25 observations. Despite the higher PCV and blood viscosity in the secondary group the mean $\mathrm{CBF}$ was significantly higher than in the primary group. Mean cerebral oxygen carriage was also significantly higher in the secondary group than in the primary group.

Effect of venesection in secondary group (table II)-After venesection the mean PCV in the secondary group was reduced by $19^{\prime \prime} \%$ from 0.613 to 0.495 . This had no significant effect on mean arterial blood pressure. Blood viscosity at the low shear rate $(0.67$, s) fell by $44 \%$ $(p<0.001)$ and at the high shear rate $(91 / \mathrm{s})$ by $33^{\circ} \%(p<0.001)$. Venesection was not associated with a significant change in mean $\mathrm{PaO}_{2}$, but the difference in $\mathrm{PaCO}_{2}$, before and after venesection was significant. Similarly, an apparently modest change in mean $\mathrm{pH}$ from 7.37 to 7.39 achieved statistical significance. The mean $P_{50}$ before 
venesection was $3.6 \mathrm{kPa}(27.3 \mathrm{~mm} \mathrm{Hg})$, and no significant difference occurred after venesection. The mean $\mathrm{CBF}$ results are also included in table II. Venesection was associated with a rise of $21^{\prime \prime} \ldots$. Mean cerebral oxygen carriage, however, actually fell from a mean value before venesection of $7.61 \mathrm{ml} / 100 \mathrm{~g} / \mathrm{min}$ to $7.26 \mathrm{ml} / 100 \mathrm{~g} / \mathrm{min}$,

\section{Discussion}

The first interesting finding of this study is that CBF is significantly higher in patients with polycythaemia secondary to hypoxic lung disease than in patients with raised PCV and

TABLE II-PCV, blood viscosity, arterial blood vases, venous $P_{50}, C B F$, and cerebral oxygen carriage before and after venesection in 12 patients with polycythaemia secondary to hypoxic lung disease. Results are means $S D$.

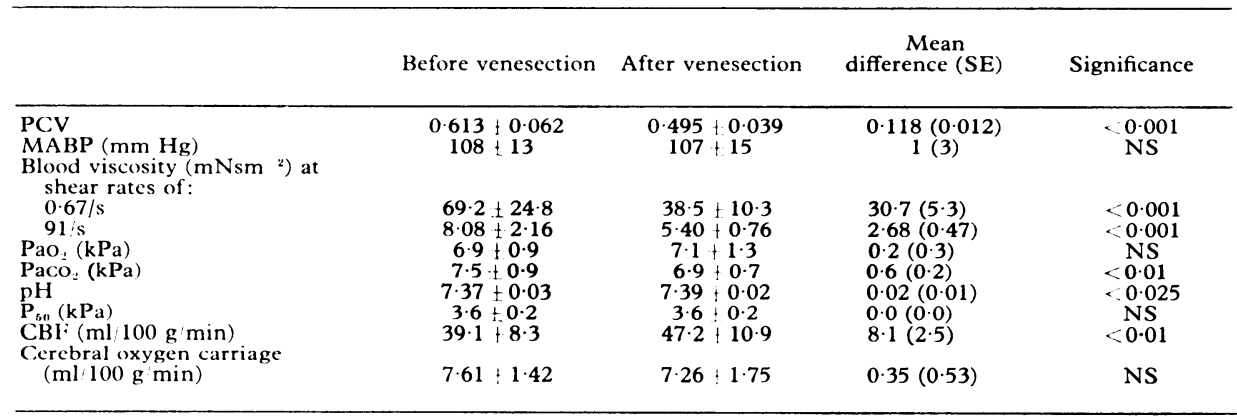
Conversion: SI to traditional units-Paco, $\mathrm{PaO}_{3}$, and $\mathrm{P}_{50}: 1 \mathrm{kPa}=7.5 \mathrm{~mm} \mathrm{Hg}$.
NS $=$ Not significant. MABP = mean arterial blood pressure

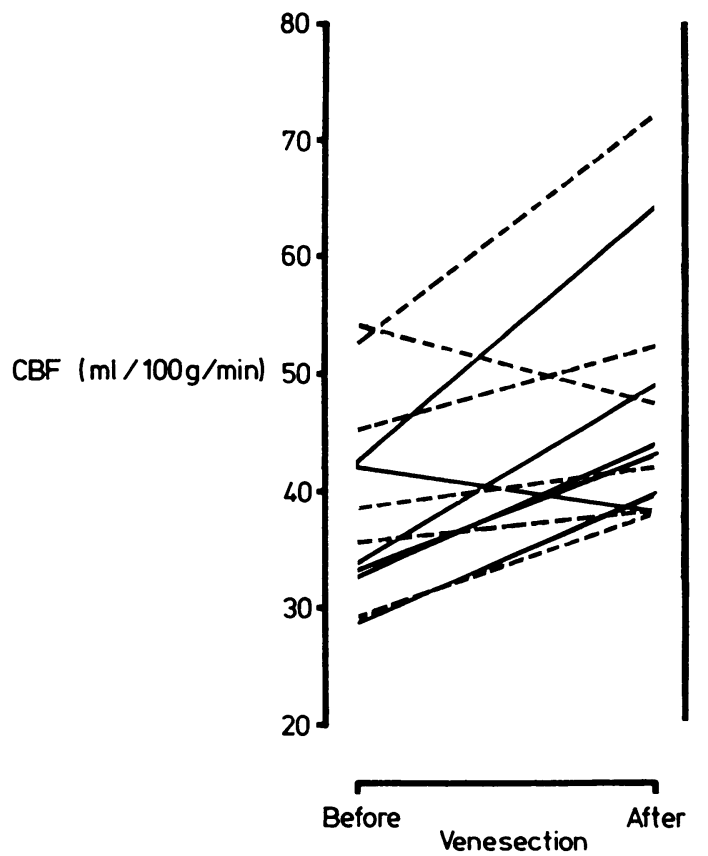

FIG 1 -CBF before and after venesection in 12 patients with polycythaemia secondary to hypoxic lung disease. Patients who reported symptomatic improvement are represented as continuous lines.

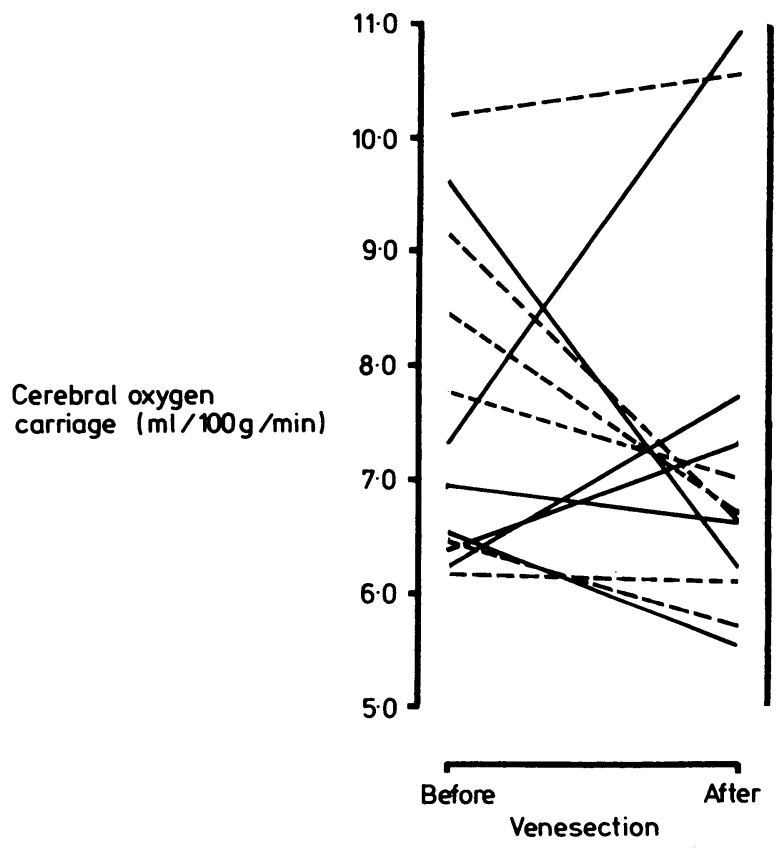

FIG 2-Cerebral oxygen carriage (CBF $\times$ arterial oxygen content) before and after venesection in 12 patients with polycythaemia secondary to hypoxic lung disease. Patients who reported symptomatic improvement are represented as continuous lines. although this did not achieve statistical significance. The four patients who reported episodes of drowsiness and confusion before venesection felt considerably better once the PCV had been lowered. This improvement was confirmed by their close relatives. In a further two patients headache was relieved, and none of the subjects reported feeling worse after PCV reduction. Figs 1 and 2 show individual changes in $\mathrm{CBF}$ and cerebral oxygen carriage with those patients who reported symptomatic improvement represented as continuous lines. Cerebral oxygen carriage did not rise in all the subjects who were benefited by venesection. normal lung function. The difference in CBF between the two groups might have been even greater had the groups been precisely matched for age, since CBF is known to decline with age. ${ }^{15}$ Maintenance of high CBF despite the raised blood viscosity suggests that the cerebral vessels are dilated, perhaps in response to the disturbance in acid-base balance. Skinhoj ${ }^{20}$ has shown that $\mathrm{CBF}$ is high in patients with chronic hypercapnia only when metabolic compensation is incomplete, and the increase correlated with the reduction in $\mathrm{CSF}$ pH. Although we 
did not measure CSF pH, it is known that CSF pH homoeostasis is often disturbed in patients with $\mathrm{PaCO}_{2}$ values greater than $7 \cdot 3 \mathrm{kPa}(55 \mathrm{~mm} \mathrm{Hg}), 21$ and over half our subjects had $\mathrm{PaCO}_{2}$ levels over that figure.

In patients with polycythaemia secondary to hypoxic lung disease, venesection leads to a consistent reduction in blood viscosity when measured at shear rates of $0.67 / \mathrm{s}$ and $91 / \mathrm{s}$, as would be expected from previous work. In spite of a marked reduction in voscosity, however, the increase in $\mathrm{CBF}$ was modest and in two patients CBF actually fell. This is presumably because of fluctuations in the other variables known to influence cerebrovascular resistance, such as $\mathrm{PaO}_{2}, \mathrm{Paco}_{2}$, and $\mathrm{pH}$. Although venesection did not affect the mean $\mathrm{PaO}_{2}$ of the group, individual variations were occasionally pronounced, and these occurred within the range of oxygen tensions known to influence CBF in normal man under conditions of experimental hypoxia." ${ }^{2 !}$ Fluctuations in $\mathrm{PacO}$., and arterial $\mathrm{pH}$ are perhaps more important in this context. Nevertheless, $\mathrm{PaCO}_{2}$ is clearly not the only factor determining CBF since venesection was associated with a fall in mean $\mathrm{PaCO}_{9}$ of $0.6 \mathrm{kPa}(4 \mathrm{~mm} \mathrm{Hg})(\mathrm{p}<0.01)$ whereas $\mathrm{CBF}$ rose by an average of $21^{\circ} \%(\mathrm{p}<0.01)$.

The improvement in mental alertness reported by four patients was dramatic and was confirmed by their close relatives. A further two patients who had complained of severe headache described complete relief of symptoms after venesection, and none of the patients was adversely influenced by treatment. Cerebral oxygen carriage was not, however, generally improved nor did it consistently increase in those patients who reported symptomatic benefit. Therefore the mental symptoms probably result from the influence of other factors on cerebral metabolism, such as the low $\mathrm{pH}$.

Patients with polycythaemia rubra vera have an increased incidence of cerebral infarction ${ }^{23}$ and this susceptibility has been related to the level of PCV. ${ }^{24}$ Low CBF may predispose to intravascular thrombosis at sites of vessel disease, and the increase in CBF which accompanies PCV reduction offers a possible method of preventing strokes. By contrast, $\mathrm{CBF}$ is not generally reduced in patients with polycythaemia secondary to hypoxic lung disease, and although PCV reduction may improve symptoms it does not appear to do so by increasing the amount of oxygen available to the brain. Patients with hypoxic lung disease may have less occlusive vascular episodes than other polycythaemic patients. There are, however, other reasons for lowering the PCV to below 0.50 , since it leads to a reduction in pulmonary vascular resistance and an improvement in work capacity, ${ }^{9} 10$ and our findings have shown that this policy will not compromise the cerebral circulation.

This work was supported by the endowment fund of St Thomas's Hospital, and additional financial help was gratefully accepted from the Leathersellers' Company.

\section{References}

1 Shaw DB, Simpson T. Polycythaemia in emphysema. $Q \mathcal{F}$ Med $1961 ; 30$ : 135-52.

${ }^{2}$ Harrison BDW. Polycythaemia in a selected group of patients with chronic airways obstruction. Clin Sci $1973 ; 44: 563-70$

${ }^{3}$ Murray JF. Arterial studies in primary and secondary polycythaemic disorders. Am Rev Respir Dis 1965;92:435-49.

${ }^{4}$ Cocking JB, Darke CS. Blood volume studies in chronic obstructive nonspecific lung disease. Thorax $1972 ; 27: 44-51$.

${ }^{5}$ Begg TB, Hearns JB. Components in blood viscosity: the relative contribution of haematocrit, plasma fibrinogen and other proteins. Clin Sci $1966 ; 31: 87-93$.

6 Thomas DJ, Marshall J, Ross Russell RW, et al. Cerebral blood flow in polycythaemia. Lancet 1977 ;ii:161-4.

${ }^{7}$ Humphrey PRD, Marshall J, Ross Russell RW, et al. Cerebral blood flow and viscosity in relative polycythaemia. Lancet 1979;ii:873-6.

8 Yates CJP, Andrews V, Berent A, Dormandy JA. Increase in leg bloodflow by normovolaemic haemodilution in intermittent claudication. Lancet 1979 ;ii:166-8.

- Harrison BDW, Davis J, Madgwick RG, Evans M. The effects of therapeutic decrease in packed cell volume on the responses to exercise of patients with polycythaemia secondary to lung disease. Clin Sci M Med $1973 ; 45: 833-47$.

10 Weisse AB, Moschos, CB, Frank MJ, Levinson GE, Cannilla JE, Regan TJ. Hemodynamic effects of staged Hematocrit reduction in patients with stable cor pulmonale and severely elevated Hematrocit levels. $\mathrm{Am}$ f Med $1975 ; \mathbf{5 8}: 92-8$.

11 Medical Research Council. Definition and classification of chronic bronchitis. Lancet $1965 ;$ i:775-8.

1.2 Pearson TC, Glass UH, Wetherley-Mein G. Interpretation of measured red cell mass in the diagnosis of polycythaemia. Scand 7 Haematol 1978; $21: 153-62$.

${ }^{13}$ Pearson TC, Wetherley-Mein G. The course and complications of idiopathic erythrocytosis. Clin Lab Haem 1979;1:189-96.

it Wetherley-Mein G. The myeloproliferative disorders. In: Hardisty RM Wetherall DJ eds. Blood and its disorders. Oxford: Blackwell Scientific Publications, 1974:1155-1206.

15 Thomas DJ, Zilkha E, Redmond S, et al. An intravenous ${ }^{133}$ Xenon clearance technique for measuring cerebral blood flow. F Neurol Sci 1979;40: 53-63.

16 Obrist WI, Thompson HK, Wang HS and Wilkinson WE. Regional cerebral blood flow estimated by ${ }^{133}$ Xenon inhalation. Stroke 1975;6: 245-56.

17 Veall N, Mallett BL. Regional cerebral blood flow determination by ${ }^{133} \mathrm{Xe}$ inhalation and external recording: the effect of arterial recirculation. Clin Sci 1966;30:353-69.

is Olesen J, Paulson OB, Lassen NA. Regional cerebral blood flow in man determined by the initial slope of the clearance of intra-arterially injected ${ }^{133} \mathrm{Xe}$. Stroke $1971 ; 2: 519-40$.

19 Veall N, Mallett BL. The partition of trace elements of xenon between human blood and brain tissues at 37 C. Phys Med Biol 1965;10:375-80.

${ }^{20}$ Skinhoj E. CBF adaptation in man to chronic hypo- and hypercapnia and its relation to CSF pH. Scand f Clin Lab Invest 1968;102, Suppl 8A.

${ }^{21}$ Huang CT, Lyons HA. The maintenance of acid-base balance between cerebrospinal fluid and arterial blood in patients with chronic respiratory disorders. Clin Sci 1966;31:273-84.

22 Olesen J. Cerebral blood flow; methods for measurement, regulation, effects of drugs and changes in disease. Acta Neurol Scand 1974;50, Suppl 57.

23 Chievitz E, Thiede T. Complications and causes of death in polycythaemia vera. Acta Med Scand 1962;172:513-23.

24 Pearson TC and Wetherley-Mein G. Vascular occlusive episodes and venous hacmatocrit in primary proliferative polycythaemia. Lancet 1978; ii, 1219-22.

(Accepted 6 fuly 1981)

HORSETAIL. Of that there are many kinds, but I shall not trouble you nor myself with any large description of them, which to do, were but, as the proverb is, To find a knot in a rush, all the kinds thereof being nothing else but knotted rushes, some with leaves, and some without. Take the description of the most eminent sort as follows.

The great Horsetail at the first springing has heads somewhat like those of asparagus, and afterwards grow to be hard, rough, hollow stalks, jointed at sundry places up to the top, a foot high, so made as if the lower parts were put into the upper, where grow on each side a bush of small long rush-like hard leaves, each part resembling a horsetail, from whence it is so called. At the tops of the stalks come forth small catkins, like those of trees. The root creeps under ground, having joints at sundry places. This (as most of the other sorts hereof) grows in wet grounds. They spring up in April, and their blooming catkins in July, seeding for the most part in Augıst, and then perish down to the ground, rising afresh in the Spring.

The herb belongs to Saturn, yet is very harmless, and excellently good for the things following: Horsetail, the smoother rather than the rough, and the leaves rather than the bare is most physical. It is very powerful to staunch bleeding either inward or outward, the juice or the decoction thereof being drank, or the juice, decoction, or distilled water applied outwardly. It also stays all sorts of lasks and fluxes in man or woman and bloody urine; and heals also not only the inward ulcers, and the excoriation of the entrails, bladder, \&c but all other sorts of foul, moist and running ulcers, and soon solders together the tops of green wounds. It cures all ruptures in children. The decoction thereof in wine being drank, provokes urine, and helps the stone and stranguary; and the distilled water thereof drank two or three times in a day, and a small quantity at a time, also eases the bowels, and is effectual against a cough that comes by distillations from the head. The juice or distilled water being warmed, and hot inflammations, pustules or red wheals, and other breakings-out in the skin, being bathed therewith, doth help them, and doth no less the swelling heat and inflammation of the lower parts in men and women. (Nicholas Culpeper (1616-54) The Complete Herbal, 1850.) 